\title{
Energy conservation and feedback metering for the automobile: Ideal requirements
}

\author{
ROBERT J. WEBER \\ Oklahoma State University, Stillwater, Oklahoma 74074
}

\begin{abstract}
To conserve gasoline in the automobile, it is desirable to have feedback on fuel consumed as a function of driving and maintenance conditions. Requirements for an ideal feedback metering system are proposed. These requirements include (1) presence of understandable units, (2) immediacy of feedback, (3) specificity of information, (4) memory of past and cumulative performance, and (5) ease of use. The metering presently available as standard equipment is found to fail all the requirements for an ideal system.
\end{abstract}

To conserve energy effectively, one must know how much energy is being used (Weber \& Price, 1980). To know how much is being used, one must have feedback on consumption. In the automobile, what are the existing forms of feedback on energy consumption, and are they adequate? Before answering this question, it is necessary to consider, based on psychological principles, what information the ideal metering system would provide for feedback. The following are suggested requirements for an effective feedback meter; the requirements are based on standard considerations in the human factors literature (Howell \& Goldstein, 1971;McCormack, 1970).

(1) Understandable Units-Information should be in understandable physical units that are sufficiently sensitive, and it should also be in monetary units for maximum motivational effect. For example, present gas gauges are far too gross; they do not provide measures of physical units such as gallons. Gasoline consumption at the moment should be in kilometers or miles per gallon and also in cost extrapolated per 1,000 miles for continuing to drive in the present manner. The 1,000 miles is arbitrary, but it should provide a cost value with some salience. If more cost emphasis is required, then 10,000 miles could be used. The meter should be capable of being set to reflect current fuel costs.

(2) Immediacy of Information-Readout of present fuel consumption should be immediate rather than delayed. Thus one may want to know the instantaneous fuel consumption in miles per gallon while accelerating in a given manner. Such information would yield dramatic feedback on the costs of jackrabbit accelerations or unnecessary idling.

(3) Specificity of Information-Information must be specific to avoid problems of aggregation that arise from averaging over different driving and vehicle conditions.

Send reprint requests to Robert J. Weber, Psychology Department, Oklahoma State University, Stillwater, Oklahoma 74078. This research was supported in part by the Education Research Foundation and in part by the Institute for Energy Analysis, both of Oklahoma State University.
Ideally, one should be able to choose the level of aggregation, ranging from the present, instantaneous fuel consumption in miles per gallon to cumulative consumption for the lifetime of the vehicle. The cumulative values should be "sealed" and would thereby become an enduring biographical feature of the car's performance in much the same way that an odometer is now an enduring record of a car's history.

(4) Memory Requirements-Some information should be retained in programmable nonvolatile memory that persists in the face of the ignition's being turned off and the battery's failing. Thus the car's fuel consumption when new or just after a tune-up could be stored in memory, and the car's present performance could be compared with its ideal performance to determine if maintenance is required. Also one could compare present conservation efforts with that of yesterday, last month, or last year. With such comparisons, our conservation efforts are likely to become more effective.

(5) Operation-The device should be easy to operate, and it should not require written records or hand calculations; otherwise many people will lose interest, and the level of aggregation will be far too high.

Note that the five ideal requirements are not sensitive to all situations. Thus fuel consumption varies with certain ephemeral conditions such as load (the combined weight of passengers plus cargo) and terrain driven on (hills or flat land). No cumulative metering system is likely to deal effectively with such factors. Two cars of the same model and mechanical condition might have quite different cumulative records for miles per gallon because they have been driven under different conditions of load and terrain. This is another reason why instantaneous readout of present miles per gallon is desirable. If the two cars give different readings of instantaneous fuel economy under the same driving conditions, then one can be further assured that their different cumulative records are due to more than ephemeral driving conditions.

With respect to the five ideal criteria, how does the present, standard-equipped automobile fare, as fitted 
Table 1

Gasoline Consumption Metering: Types of Feedback Presently Available

\begin{tabular}{|c|c|c|}
\hline Device & Information/Units & Comment \\
\hline (1) Odometer & Cumulative miles traveled, fairly precise measure. & No direct information on fuel consumption. \\
\hline (2) Speedometer & Current speed in miles per hour, fairly precise. & $\begin{array}{l}\text { No direct information on fuel consumption, } \\
\text { but high speeds are associated with poor } \\
\text { fuel economy. }\end{array}$ \\
\hline (3) Gas Gauge & Needle gauge, very gross, no obvious units. & $\begin{array}{l}\text { Because units are lacking and precision is } \\
\text { low, not very useful for conservation } \\
\text { purposes. }\end{array}$ \\
\hline (4) Gas Pump Gauge & Gallons (nearest .1 gallon), fairly precise. & $\begin{array}{l}\text { Amount of fuel input to car; must be written } \\
\text { down to be useful. }\end{array}$ \\
\hline (5) Pencil, Paper & Cumulative fuel use in gallons. & $\begin{array}{l}\text { Written record from gas pump (very incon- } \\
\text { venient). }\end{array}$ \\
\hline (6) Pencil, Paper, Calculator & Miles per gallon, very gross. & $\begin{array}{l}\text { A derived measure of fuel efficiency; relies } \\
\text { on written record (very inconvenient) and } \\
\text { imprecise criterion of when gas tank is } \\
\text { filled. High level of aggregation due to } \\
\text { averaging over many different driving } \\
\text { conditions. }\end{array}$ \\
\hline
\end{tabular}

with odometer, speedometer, and crude gas gauge? Table 1 presents a summary. It indicates that not one of the ideal metering requirements is satisfied by existing standard equipment. Is this unfortunate lack of capability for feedback metering due to expense? Probably not. For example, one commercial product, offered by an independent electronics company and based on a microprocessor, comes very close to the requirements set for an ideal feedback metering system. It is called the CompuCruise (J. C. Penney Spring and Summer Catalog, 1980 , p. 728 ). Apparently, it can digitally display amount of fuel consumed since last fill-up, fuel consumed on last trip, total remaining fuel, and fuel required to arrive at destination based on the current speed and fuel consumption. It also displays instantaneous and average miles per gallon, as well as temperature monitoring, time, and speed. It falls short of the ideal criteria in not having monetary feedback information (probably the most important feedback for conservation behavior) and perhaps in not having some of the desired memory capabilities. It sells for $\$ 139$ and could probably sell for much less if mass produced.

As feedback meters approach more closely the ideal requirements, it is likely that people will become more energy and cost conscious in their driving practices, better maintenance practices will develop, and consumer demand for more efficient cars will increase. The competition among auto manufacturers may even become more rational.

\section{REFERENCES}

Howell, W. C., \& Goldstein, I. L. (Eds.). Engineering psychology: Current perspectives in research. New York: Meredith, 1971.

J. C. Penney. Spring and summer catalog, 1980.

McCormack, E. J. Human factors engineering. New York: McGraw-Hill, 1970.

Weber, R. J., \& Price, J. M. Knowledge of energy consumption. Bulletin of the Psychonomic Society, 1980, 15, 267-268.

(Received for publication August 26, 1980.) 